\title{
Biological remediation of roadside areas
}

\author{
Elena Grebenshchikova ${ }^{1, *}$, Natalia Shelkovkina ${ }^{1}$, and Natalia Gorbacheva ${ }^{1}$ \\ ${ }^{1}$ Far Eastern state agrarian University, Blagoveshchensk, Russia.
}

\begin{abstract}
During the construction of highways, significant damage is caused to the environment: the soil cover is degraded, vegetation cover and the natural landscape are destroyed. The issue of minimizing the negative impact of this direction on the environment was not given enough attention. Therefore, one of the main issues of environmental protection is the timely implementation of works on reclamation of disturbed lands. Land areas of temporary allotment for road construction that are subjected to mechanical impact after the stage of technical reclamation are subject to biological reclamation, which is aimed at landscaping the roadside area. To achieve these goals, we used the method of developing measures for the reclamation of disturbed land during the construction of the highway. Activities on biological remediation can be performed as a result of: the serial complexity of the species composition of plant communities, which has long co-exist with man-made recultivated territories; the launch of the rehabilitation process which can be carried out simultaneously in a multispecies complex of phytocenosis, suggesting further its sustainable functioning. As a result of biological reclamation measures, using crops that are resistant to pollutants and meliorants, it is possible to gradually reduce the content of pollutants in the soil due to natural self-cleaning processes as a result of removal of elements by plants and their leaching outside the root layer of the soil.
\end{abstract}

\section{Introduction}

Highways that are linear structures play an important role in the improvement of a locality. For the construction of linear structures, significant land plots are allocated, where herbaceous and woody-shrub vegetation grows. To stabilize the state of the natural environment, a comprehensive review of these objects is carried out using various engineering solutions with a biological component. Plants are becoming an integral, environmentally active part of engineering solutions.

According to GOST 17.5.3.04 " nature Protection (SSOP). Lands. General requirements for reclamation" the road, as a hub of one of the mass sources of environmental impact-road transport, has a multi-sided impact.

Research by many scientists shows that impacts on environmental components can occur over a long period of time during the operation of roads. In turn, road maintenance is carried out according to the recommendations for the seasons. In many countries, in winter, the use of deicing materials is common, which contain different chemical composition

${ }^{*}$ Corresponding author: grebenshchikova72@mail.ru 
(chlorides, nitrates, phosphates, etc.) that has a harmful effect on the components of the environment: soil, ground and surface water, vegetation. American scientists have found that the use of salts only for one season leads to an increase in the content of sodium and chlorine in the soil and nearby reservoirs [1]. To reduce the influence of this factor, it is advisable to use biological reclamation, namely the restoration of vegetation corresponding to natural and climatic zones, forest reclamation zoning, and soil zones. Studies conducted in this area prove the protective value of vegetation cover in improving the structure and water permeability of the soil as a result of the decomposition of root residues [2].

As a result of research conducted in Germany, it was found that most trees growing along highways die as a result of the use of salts [3]. Plants react differently to stressors, which depends both on the functioning of antioxidant enzymes and on the accumulation of low-molecular-weight antioxidants in cells [4]. Due to the death of roadside trees, the concentration of carbon monoxide increases [5].

Of the highway crossing within the village, to maximize the impact of noise that adversely affects human health. When planting green spaces, the impact of noise is reduced, as the foliage of woody plants has a high sound-reflecting ability and improves the environmental characteristics of the territory. The noise-absorbing ability is most pronounced in maple, Linden, poplar, oak, and birch [6].

The dominant negative result of the functioning of highways is atmospheric pollution. Volatile chemicals released to the environment from automobile emissions include carbon monoxide (CO), nitrogen oxides, volatile organic compounds, sulfur dioxide (SO2), particulate matter from exhaust gases and road dust, lead $(\mathrm{Pb})$, and toxic substances including benzene, butadiene, and formaldehyde. Many studies have shown that lower air quality causes adverse effects on the health and quality of life of people working and living near highways, in particular exposure to ultrafine particles $[7,8]$. Green spaces can play the role of a natural filter, purifying the air from harmful impurities. Especially effective is the planting of the most resistant to pollution rocks with a large leaf surface and a large volume of gas absorption and dust deposition. Vegetation is also used to reduce air pollution by harmful and pathogenic microorganisms [9-11].

Road construction and maintenance activities pose a significant threat to water quality in water bodies, which is confirmed by numerous studies $[12,13]$.

The soil along the roadsides is polluted by vehicle emissions $[14,15]$. The source of pollutants entering the soil can be spills of technical liquids along roads during repair work, which together with surface runoff move long distances from the road [16]. Areas of soil adjacent to roads are subject to wind and water erosion. An effective measure of soil erosion protection is the creation of a vegetation cover of grasses with a developed root system that penetrates to a depth of $20 \mathrm{~cm}$ or more and forms a dense and durable turf layer, as well as landscaping used to protect roads from the destructive effects of growing ravines, erosion and destruction by mudslides, as well as to combat landslides.

All of the above functions of green spaces are closely related to each other and, of course, should be combined. To achieve maximum effect, the principle of reasonable expediency should be used, which includes a combination of all functions and consideration of environmental, aesthetic and economic factors.

\section{Research Materials and methods}

The area of environmental impact during road reconstruction was determined in accordance with the"Guidelines for environmental impact assessment (EIA) for the design, construction, reconstruction and operation of road facilities".

The calculation of atmospheric air pollution by harmful substances during construction was performed in the software package "uprza Ecologist" version 3.0, which implements 
the provisions of the " Methodology for calculating concentrations in the atmospheric air of harmful substances contained in the emissions of enterprises (RD 52.04.212-86)". The calculation took into account data from the Amur regional center for Hydrometeorology and environmental monitoring on background concentrations of pollutants in the atmospheric air in the Bureysky district of the Amur region. A calculated rectangle with a grid step of $100 * 100$ is used for the calculation. Dispersion calculations were performed for dangerous wind direction and speed. Dangerous wind directions and speed were selected automatically by the PC.

The calculation of maximum and equivalent sound levels was performed in accordance with current regulations in accordance with GOST 23337-2014 " Noise. Methods for measuring noise in residential areas and in residential and public buildings."

\section{Results}

We considered a section of the highway of the village of Vinogradovka located in the Bureysky district of the Amur region. Bureysky district is located in the South-East of the Amur region in the basin of the lower and partly middle reaches of the Bureya river. To characterize the climatic conditions of the area, we used data from long-term observations of the weather stations Arkhara, Malinovka, as well as data from the scientific and applied reference book on climate. The climate of the Bureysky district of the Amur region is influenced by the monsoon and is caused by the influence of the Asian continent and the Pacific ocean (a significant distance from the sea and proximity to the center of the Asian continent gives the climate of the region many continental features).

A crucial role in the formation of the wind regime of the territory under consideration is played by the General circulation of air masses, which is characterized by seasonal changes in wind directions. The prevailing wind direction is North-West and South-East. During the long winter, the wind regime in General for the Amur region is determined by the presence of a vast cold anticyclone, located in its Central part in the TRANS-Baikal region and in the Northern regions of Mongolia. Due to this, the North-Western and Western air mass transfer is established on the specified territory up to high altitudes. In the summer, the Eastern and South-Eastern circulation is expressed over the territory of the Amur region. However, in the territory under consideration, in conditions of hilly, rough terrain, the direction of winds in summer is very unstable, which is associated with the deformation of air flows under the influence of terrain. In spring and autumn, there is an increase in cyclonic activity - southern cyclones move through Mongolia and Manchuria in series to the territory of the Amur region, then to the Khabarovsk territory and the sea of Okhotsk. The highest number of days with strong winds (with a wind speed equal to or greater than $15 \mathrm{~m} / \mathrm{s}$ ) reaches 21 days per year. Based on long-term observations at the Arkhar weather station, wind repeatability forecasts for the coldest and warmest month of the year were constructed, which are shown in figure 1.

The moisture regime of the described territory is characterized by a pronounced seasonality. During the monsoon circulation in winter, conditions are created that are unfavorable for the transfer of moisture from the warmer ocean to the mainland. Here, winter is characterized by low clouds and the least amount of precipitation. Summer is mostly wet and rainy. The average annual precipitation in the area under consideration is $635 \mathrm{~mm}$. Precipitation is unevenly distributed throughout the year. The minimum precipitation falls in January - February, the maximum-in July - August. The average date of occurrence of snow cover 20-25 Oct. The average snowfall date is April 10. The average maximum height of the snow cover is $23 \mathrm{~cm}$, the maximum reaches $55 \mathrm{~cm}$. The height of the snow cover increases throughout the winter and the highest is observed in December February. The average precipitation in July-August is $131-137 \mathrm{~mm}$. 

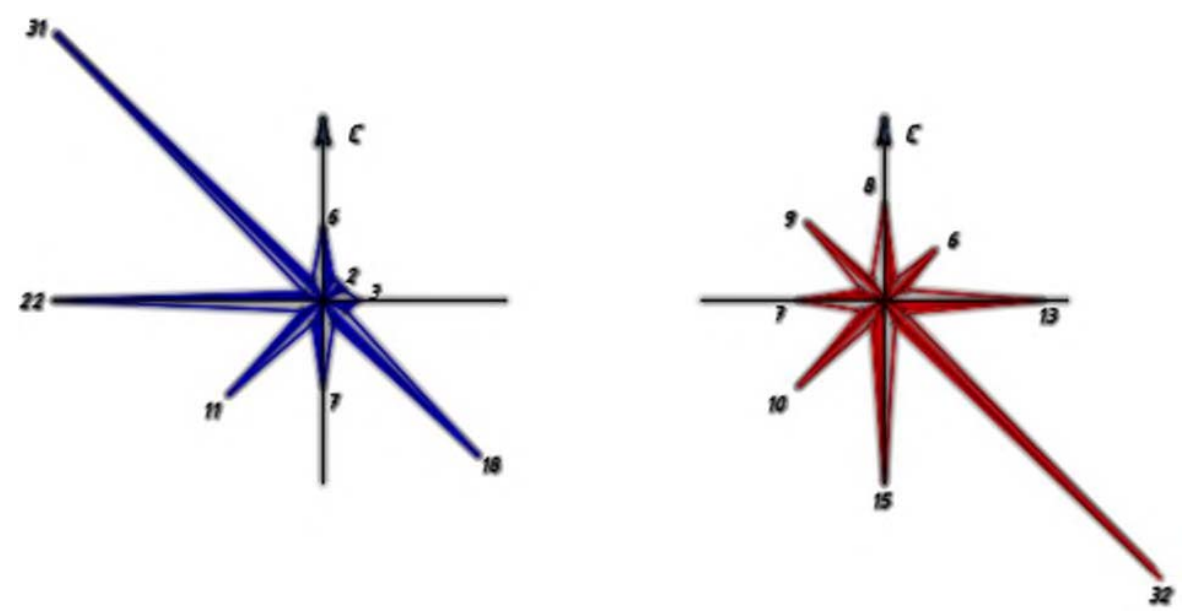

Fig. 1. Wind frequency index in \% for the period (January and July).

The continental climate has a significant influence on the temperature regime. This is evident in the pronounced difference between winter and summer air temperature values. The absolute minimum air temperature is $-50{ }^{\circ} \mathrm{C}$, the absolute maximum is $40{ }^{\circ} \mathrm{C}$. The average temperature of the coldest five days is $-36^{\circ} \mathrm{C}$. The average temperature of the coldest days is $-40^{\circ} \mathrm{C}$ the Duration of the period with positive air temperatures is $192-194$ days. The transition of air temperature through $0^{\circ}$ in the spring occurs on average on April 6. The duration of the frost-free period is 193 days.

According to the nature of surface runoff and the degree of moisture, the site belongs to type 2 according to SP 34.13330.2012.

The road, as a hub of one of the mass sources of environmental impact - road transport, has a multi-sided impact. This object belongs to the III ecological hazard class according to GOST 17.5.3.04-83.

The main objects of environmental impact are the following components: atmospheric air, surface runoff, flora and fauna, geological environment, soil, landscape aesthetics.

The area of occupied land for temporary use was 0.236 ha. The vegetation cover of the surrounding area is dominated by veynik, wormwood, various clovers, common tansy, various sedges, bonfire without a tail, marsh bluegrass, meadow fescue, plantain large, annual bluegrass and others. Shrubs and trees of the following species composition: Daurian larch, Ayan spruce, white birch, aspen.

During construction and operation, three types of environmental impact can be distinguished: operational - manifested over a long period of time; transport - from motor vehicles as mobile sources of impact; construction - from technological processes of construction. Linear structures that require a large amount of earthwork have an impact on the terrain and conditions of groundwater distribution, which in turn affect the root system of the natural landscape.

Adjacent to the road areas are allocated land not included in the allotment, but which are also environmental impacts: area of impact, protection strip, the reserve-technological strip.

Zone of influence-transport pollution can exceed background levels of air, water, and soil pollution without reaching the limit values. But at the same time, individual changes in surface and underground runoff, microclimate affect vegetation and animals, and gradually lead to changes in the landscape.

Protective strip-transport pollution during the billing period may exceed the established maximum permissible concentrations or sanitary standards. Soil pollution gradually 
accumulates and can reach unacceptable values, and significant changes in natural systems can occur.

Reserve-technological lane - an area adjacent to the road, within the boundaries of which the maximum permissible standards for air, soil, and water pollution are constantly exceeded.

According to the "Guidelines for environmental impact assessment (EIA) in the design, construction, reconstruction and operation of road facilities", the dimensions of these zones are the values shown in table 1 .

Table 1. Sizes of zones of influence Distance from the edge of the roadway, $\mathrm{m}$.

\begin{tabular}{|c|c|c|}
\hline \multirow{2}{*}{$\begin{array}{c}\text { Territories of } \\
\text { environmental } \\
\text { impact }\end{array}$} & $\begin{array}{c}\text { Distance from the edge of the carriageway, } \mathrm{m} \\
\text { free distribution of } \\
\text { influence }\end{array}$ & $\begin{array}{c}\text { If there are obstacles } \\
\text { (terrain, buildings, } \\
\text { forest) }\end{array}$ \\
\hline $\begin{array}{c}\text { Zone of } \\
\text { influence }\end{array}$ & 2000 & 1000 \\
\hline $\begin{array}{c}\text { Shelter belt } \\
\text { The reserve- } \\
\text { technological } \\
\text { strip }\end{array}$ & 150 & 90 \\
\hline
\end{tabular}

During the reconstruction of the road, various heavy equipment works, which has a negative impact on the natural environment. Pollutants released from construction equipment enter the air, then fall as precipitation on the soil and vegetation, causing environmental damage to the natural landscape located on the roadside. We conducted research to determine the emission of pollutants from certain types of construction equipment (Fig. 1).

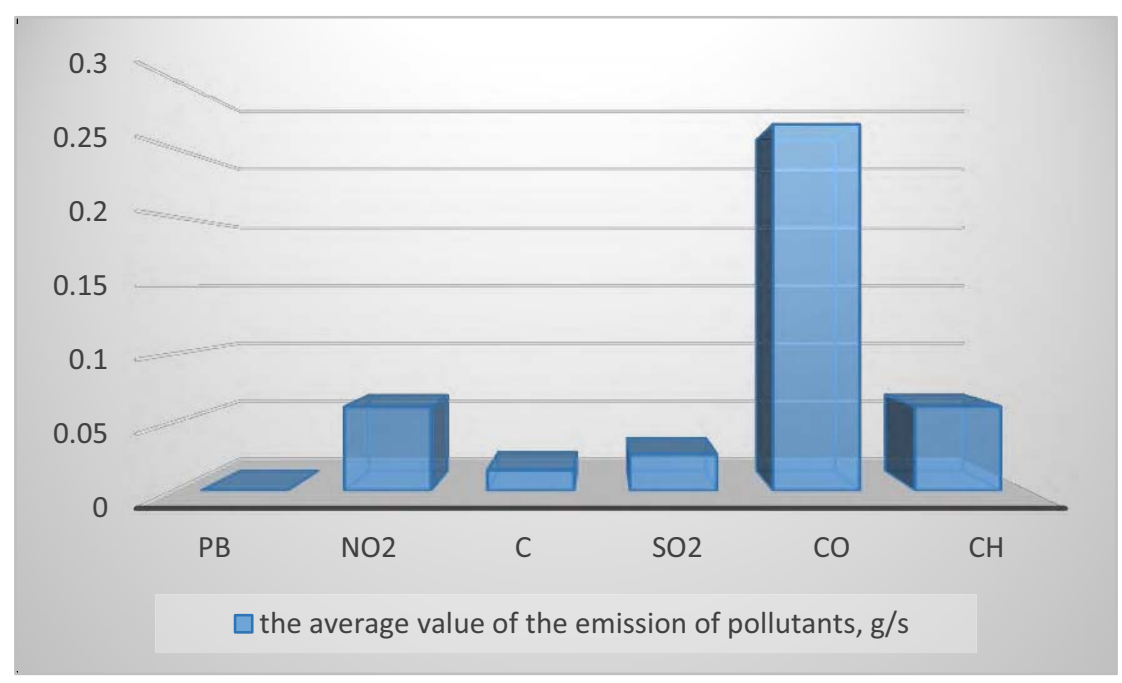

Fig. 1. Average emission of pollutants from certain types of construction equipment.

The emission of pollutants in the atmosphere depends on the type of engine of construction equipment and on background air pollution. According to the data of the Amur regional center for Hydrometeorology and environmental monitoring, background concentrations of pollutants in the air were: dust- $0.14 \mathrm{mg} / \mathrm{m} 3$; nitrogen dioxide- 0.06 
$\mathrm{mg} / \mathrm{m} 3$; sulfur dioxide $-0.011 \mathrm{mg} / \mathrm{m} 3$; carbon monoxide $-1.8 \mathrm{mg} / \mathrm{m} 3$. The main pollutants released into the air by construction equipment are: nitrogen dioxide (0301), soot (0328), sulfur anhydride (0330), carbon oxide (0337), and hydrocarbons (2732). These substances belong to hazard class 2,3 and 4 according to hygiene standards. The concentration of pollutants in the atmosphere in comparison with the maximum single maximum permissible concentration is shown in figure 2 .

From the calculations performed, it can be concluded that the maximum permissible concentration of the considered pollutants during the work period is normal: 0301 nitrogen dioxide-0.65 MPC; 0328 soot-0.35 MPC; 0330 sulfur dioxide - 0.065 MPC; 0337 carbon oxide - 0.61 MPC; 2732 kerosene - 0.16 MPC; 2754 hydrocarbons - 0.28 MPC. Emissions of inorganic dust can be offered as a temporary agreed emission levels. In General, the assessment of the impact of road reconstruction on the state of atmospheric air is negative, since even a small amount of pollutants in the atmosphere causes pollution of the roadside area and, as a result, biological remediation.

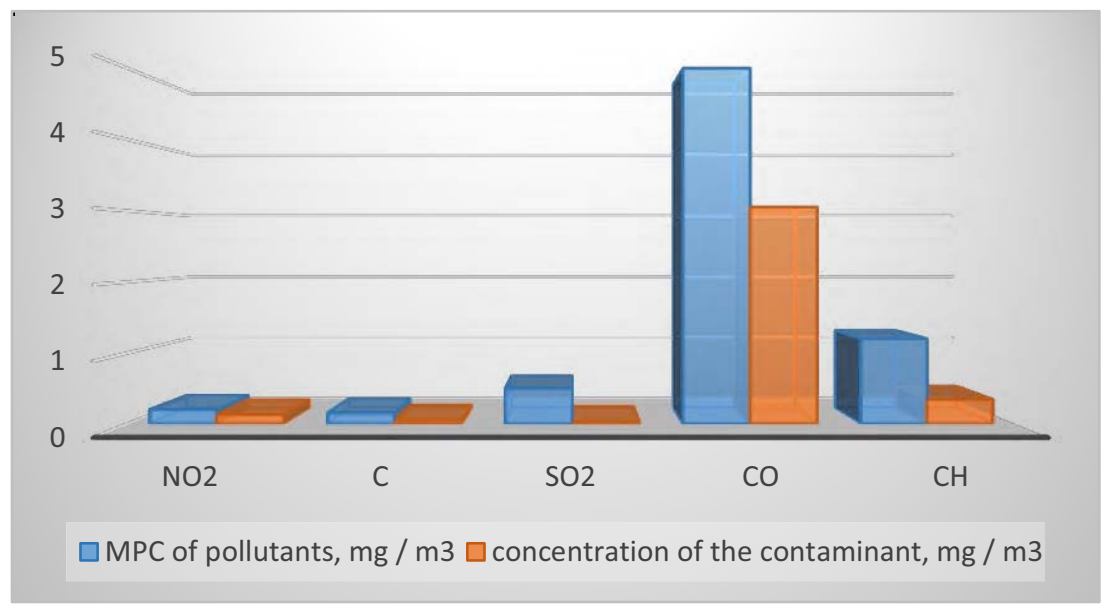

Fig. 2. Concentration of pollutants in the atmosphere during the operation of construction equipment.

In addition to the emission of pollutants into the atmosphere when working with construction equipment and motor transport, noise is created, which affects the violation of acoustic comfort of a person. According to sanitary standards, the noise level for localities should not exceed $55 \mathrm{dBA}$ (during the day) and $45 \mathrm{dBA}$ (at night). The noise generated in the process of road reconstruction works is formed as a result of complex summation of noise from various sources of different sound power. The noise background from motor transport was assessed by the CENTER 321 noise meter in clear weather with a wind speed of no more than $4 \mathrm{~m} / \mathrm{s}$. The results of the assessment showed that the total noise level during operation of the equipment was 97 DBA. Roadside vegetation could reduce the impact of such noise on human health, but it is not enough in this area. Therefore, when completing construction work, it is necessary to select the vegetation of the roadside area for this climate zone.

Negative impact on the soil during road reconstruction is an inevitable consequence. During construction work, oil products are lost to the soil cover from construction equipment, which leads to their contamination. There is also a violation of the soil cover and terrain by tracked and wheeled transport. Waste generated during road reconstruction is classified as hazard class 3.4 and 5. In case of non-compliance with the rules for storage of hazard class 3 waste (used engine oil, used transmission oil, used hydraulic oil that does not contain Halogens, other waste paper and cardboard, cleaning material contaminated with oils (oil content of $15 \%$ or more), wood sawdust contaminated with mineral oils (oil content 
of $15 \%$ or more)) soil is polluted with substances containing petroleum products; 4 and 5 hazard class waste (household garbage from premises, unsorted (except for bulky), waste (sediment) from cesspools, scrap metal unsorted, soil from clearing, wood waste) littering, environmental pollution domestic sewage pollution of soil iron oxides.

The impact on vegetation during construction is expressed in the cutting down of tree and shrub vegetation on areas of permanent and temporary land allotment, which must be restored after the work has been completed, that is, to conduct biological reclamation of the roadside landscape.

Studies of the impact of road reconstruction on environmental components have shown that after the completion of construction work, it is necessary to conduct biological remediation of the roadside area.

The biological stage of reclamation will be carried out by natural selection of the species composition of the plant community. The vegetation cover of the surrounding area is dominated by blueberry (Calamagrostis $x$ acutiflora), wormwood (Artemisia absinthium), various clovers (Trifólium), common tansy (Tanacétum vulgáre), various sedges (Cárex), bonfire (Brōmus inērmis), swamp bluegrass (Póa palústris), meadow fescue (Festuca pratensis), large plantain (Plantago major L.), annual bluegrass (póa Ánnua) and others. Shrubs and trees of the following species composition: Daurian larch (Lárix gmélinii), Ayan spruce (Picea jezoensis), white birch (Betula alba), aspen (Pópulus trémula). The main requirement when choosing a variety of crops is the use of local flora species that are ecologically adapted to the conditions of existence in this climate zone.

In the first stages of forest reclamation, fast-growing breeds are used. The survival and growth of tree and shrub vegetation depends mainly on the granulometric composition of the rock and its $\mathrm{pH}$. On the roadside section of the highway, the $\mathrm{pH}$ is in the range of 6.00.5 , so it is rational to plant annual seedlings. To select vegetation, it is necessary to divide it into the main one, which performs the main protective function, and the accompanying one, which performs an auxiliary role. Shrubs perform a soil-protecting role, increase soil fertility.

We selected the following woodlands: tree crops-common pine, birch; shrubs. White birch plays an important anti-erosion role, bioecological characteristics: frost resistance - 1 point, drought resistance-1 point, light-loving-1 point, demanding fertility 1-2 points, growth rate 1-2 points, reclamation properties-2 points, biological utility-2 points. Bioecological characteristics of pine: frost resistance - 1-2 points, drought resistance-1 point, light-loving - 2 points, demanding fertility-1 point, growth rate - 1-2 points, reclamation properties- 2 points, biological utility-1 point. Bioecological characteristics of the Manchurian nut: frost resistance-2 points, drought resistance-2 points, light-loving - 2 points, demanding fertility-1 point, growth rate- 2 points, reclamation properties- 2 points, biological utility-2 points. Bioecological characteristics of Amur lilac: frost resistance-2 points, drought resistance-2 points, light-loving-1 point, demanding fertility-1 point, growth rate - 1-2 points, reclamation properties-2 points, biological utility-2 points [17].

By eliminating sources of further soil contamination, rehabilitating land and occupying areas with crops that are resistant to pollutants and meliorants, it is possible to gradually reduce the content of pollutants in the soil due to natural processes of self-cleaning as a result of the removal of elements by plants and their leaching out of the root layer of the soil.

\section{References}

1. A. Langille One seasons salt accumulation in soil and trees adjacent to a highway. Hart science 11, 6, 575-576 (1976) 
2. A. Verspoor Wayne Highway drainage and its effect on Michigan Waters, Michigan Highway Conf. Proc.: 56th Grand Rapids. Mech., 45-50 (1971)

3. L. Steubing, Immissions belastung der straßenrandvegetation. Natur und Land sch. 51, 9, 239-244 (1976)

4. W. Jorgin, Die wertschatrung der Natur in der Kosten - Nutzen - Analyse Int. Verehrsm 41(2), 103-104 (1989)

5. A. Modi and N. P. Shinkar, Environmental impact assessment of road from Ujjain to Jaora. International Journal of Engineering and Advance Technology 1, 2249-8958 (2012)

6. G. Kozlov, M. Pushkarev, Forecast of the morphological composition of municipal solid waste in Moscow (Russia). E3S Web of Conferences 135, 01053 (2019) doi:10.1051/e3sconf/201913501053

7. R. Beelen, R. G Hoek, P. A. Vanden-Brand, R. A. Goldbohm, Fischer P and Schouten LJ. Long-term exposure to traffic-related air pollution and lung cancer risk. Epidemiology, 19, 702-710 (2008)

8. F. Laden, J. Schwartz, F. E. Speizer FE Reduction in fine particulate air pollution and mortality: Extended follow-up of the Harvard six cities study American Journal of Respiratory and Critical Care Medicine, 173, 667-672 (2006)

9. V. A. Gorokhov Green nature of the city, 528 (2005)

10. V. V. SLEPYKH Antimicrobial and ionizing properties of woody vegetation under the influence of abiotic factors, 39 (2010)

11. M. V. Kochergina, A. S. Darkovskaya Phytoncidal properties of coniferous introducents of specially protected natural territories of Voronezh Byull. bot. Saratov state garden. UN-TA, 84-88 (2010)

12. G. S. Shyu, B. Y. Cheng and W. T. Fang. The Effect of Developing a Tunnel across a Highway on the Water Quality in an Upstream Reservoir Watershed Area- A Case Study of the Hsuehshan Tunnel in Taiwan International Journal of Environmental Research and Public Health Public Health, 9, 3344-3353 (2012)

13. A. W. N. Abewickrema, R. W. N. Amanthika, Tennakoon RK, Tennakoon AH, Caldera HMM, Safnas M and Miguntanna NP. Assessment of water quality impacts of highway and road construction projects, South Asian Institute of Technology and Medicine Research Symposium on Engineering Advancements-RSEA, 136-143. (2013)

14. H. M. Nase, S. Sultana, Gomes R and Noor S. Heavy metal pollution of soil and vegetable grown near roadside at Gazipur. Bangladesh Journal of Agricultural Research, 37(1), 9-17 (2012)

15. E. Padoan, C. Romè, F. Ajmone-Marsan. Bioaccessibility and size distribution of metals in road dust and roadside soils along a peri-urban transect, Science of The Total Environment, 601-602 89-98 (2017)

16. Toxicity evaluation of highway stormwater runo M. Kayhaniana; and M.L. Johnsonb Scientia Iranica A 26(4), 2133, 2153 Sharif University of Technology Scientia Iranica (2019)

17. E. A. Grebenshchikova, N. A. Gorbacheva Improvement of roadside territory in the construction of linear structures. Materials of the $X$ international forum: Protection and rational use of forest resources, 119-122 (2019).

18. N. S. Shelkovkina, E. A. Grebenshchikova, N. A. Gorbacheva Recultivation of disturbed land in the construction of highways. Bulletin of the Kursk state agricultural Academy, 1, 29-35 (2019) 